\title{
PENGARUH PENGGUNAAN MEDIA BANGUN RUANG TRANSPARAN TERHADAP PEMAHAMAN SISWA DALAM MATERI BANGUN RUANG DI SEKOLAH DASAR
}

\author{
Ari Shinta Nafirin \\ Program Studi PGSD, Fakultas Ilmu Pendidikan, Universitas Hasyim Asy’ari \\ Arishintanafirin@gmail.com \\ Kamidjan \\ Fakultas Ilmu Pendidikan, Universitas Hasyim Asy'ari \\ Claudya Zahrani Susilo \\ Program Studi PGSD, Fakultas Ilmu Pendidikan, Universitas Hasyim Asy’ari
}

\begin{abstract}
Abstrak
Penelitian ini bertujuan untuk mengetahui pengaruh media bangun ruang transparan terhadap pemahaman siswa. Populasi dalam penelitian ini adalah seluruh siswa kelas 2 SDN Ngoro 2 yang berjumlah 53 siswa yang terbagi 27 siswa untuk kelas kontrol dan 26 siswa untuk kelas eksperimen. Penelitian ini merupakan penelitian eksperimen semu dengan desain penelitian nonquivalent control group design. Dalam penelitian ini data yang diperlukan adalah data tentang kemampuan pemahaman yang diperoleh melaluites pemahaman bangun ruang. Data dianalisis secara deskriptif dan untuk engujian hipotesis digunakan uji $\mathrm{T}$ dua sampel. Hasil yang diperoleh dari analisis menunujukkan bahwa pemahaman materi bangun ruang siswa yang mengikuti pembelajaran dengan media bangun ruang transparan lebih baik dari pemahaman materi bangun ruang siswa yang mengikuti pembelajaran konvensional.
\end{abstract}

KataKunci: Media Bangun Ruang Transparan, Pemahaman, Bangun Ruang

\begin{abstract}
This study aims to determine the effect of media on building transparent space on students' understanding. The population in this study were all 2nd grade students of SDN Ngoro 2, amoungting to 53 students divided into 27 control class students and 26 experiment class student. This research is a quasi experimental study with a non quivalent control group design research design. In this research, what is needed is data about the ability of comprehension obtained through tests of understanding the matter of building space. The data in the analyst are descriptive and for hypothesis testing the T sample is used for two samples. The result obtained from the analysis show that understanding the material in building the space of students who follow learning with media builds transparent space is better than understanding the material in building the space of students who take conventional learning.
\end{abstract}

Keywords: Media Build Transparent Space, Understanding, Building Space

\section{PENDAHULUAN}

Dalam kurikulum 2013 matematika merupakan salah satu mata pelajaran yang abstrak. Keabstrakan matematika yang ada di sekolah dasar salah satunya adalah mengenai materi bangun ruang yang termasuk ke dalam ruang lingkup geometri. Bangun ruang yang dipelajari yaitu tentang sisi, rusuk, dan titik sudut. Materi tentang sisi, rusuk, dan titik sudut merupakan suatu materi yang abstrak sehingga perlu dijelaskan secara konkret kepada siswa. Jika siswa diberikan penjelasan secara langsung mengenai sisi, rusuk, dan titik sudut maka kemungkinan yang terjadi siswa tidak akan bisa membayangkan karena siswa belum mampu dalam berfikir secara abstrak.

Salah satu cara agar dapat mengubah materi yang abstrak menjadi konkret sesuai dengan tahap perkembangan kognitif siswa adalah dengan menggunakan media pembelajaran. Media pembelajaran 
merupakan alat yang dapat digunakan guru dalam mengubah materi yang abstrak menjadi konkret, mengubah suasana pembelajaran menjadi menyenangkan sehingga membuat siswa aktif dalam kegiatan pembelajaran, pembelajaran tidak dipusatkan pada guru dikarenakan siswa ikut terlibat langsung dalam kegiatan pembelajaran (Sanaky dalam Sundayana, 2015:9). Oleh karena itu, penggunaan media pembelajaran sangat diperlukan untuk membantu siswa dalam mengubah sesuatu yang abstrak menjadi sesuatu yang konkret.

Dari uraian di atas, maka dibutuhkan sebuah media pembelajaran yang cocok untuk kegiatan pembelajaran. Oleh sebab itu peneliti menggunakan media 3 dimensi berupa bangun ruang transparan untuk melakukan penelitian dengan judul “ Pengaruh Penggunaan Media Bangun Ruang Transparanh Terhadap Pemahaman Siswa Tema 4 Subtema 3 Materi Bangun Ruang Kelas II SDN Ngoro 2".

Berdasarkan masalah yang akan diteliti di atas, maka tujuan penelitian ini adalah untuk mengetahui pengaruh media bangun ruang transparan terhadap pemahaman siswa kelas II di SDN Ngoro 2.

Kata media berasal dari bahasa Latin dan bentuk jamak dari medium yang dapat diartikan sebagai perantara. Perantara dalam artian sebagai alat yang digunakan untuk menyalurkan informasi dari pengirim pesan yang dalam hal ini adalah guru kepada penerima pesan yang dalam hal ini adalah siswa. Menurut Trianto (2011:199) media merupakan tempat informasi yang digunakan untuk menyalurkan informasi dari pemberi informasi lalu disalurkan kepada penerima informasi. Informasi berupa pesan pembelajaran, dan tujuan pengiriman informasi adalah dapat terjadinya proses belajar yang lebih baik dan sempurna. Penyalur informasi yang dimaksud adalah guru, sedangkan yang menerima informasi adalah siswa. Guru dan siswa saling berpengaruh demi terwujudnya tujuan pembelajaran yang baik dan sempurna.
Media pembelajaran merupakan perantara yang digunakan oleh guru untuk memberikan materi ajar kepada siswa saat proses pembelajaran. Pengertian pembelajaran sendiri adalah proses memberi dan menerima informasi atau yang disebut dengan komunikasi antara guru, siswa dan segala kebutuhan yang digunakan pada saat pembelajaran. Dengan kata lain kegiatan komunikasi tidak akan pernah tercapai jika tidak ada bantuan berupa alat yang digunakan untuk menyampaikan pesan kepada penerima pesan. Beberapa definisi media pembelajaran yang telah dipaparkan, dapat ditarik kesimpulan bahwa media pembelajaran adalah suatu alat yang digunakan untuk membantu guru dalam menyampaikan informasi pembelajaran yang dalam hal ini adalah berupa materi pembelajaran, informasi tersebut akan disampaikan kepada penerima informasi yang dalam hal ini adalah siswa. Adanya media sebagai perantara informasi bertujuan untuk memudahkan guru dalam memberikan materi kepada siswa, sehingga siswa lebih mudah dalam menerima pembelajaran yang disampaikan oleh guru.

Peranan Media pembelajaran yang dipaparkan oleh Kemp dan Dayton (dalam Sanjaya, 2012:210) sangat penting terhadap proses pembelajaran. Diantara peranan tersebut menurut kedua ahli adalah kegiatan pembelajaran lebih interaktif antara guru dengan siswa sehingga pembelajaran menjadi lebih menarik, hal ini berdampak pada peran guru yang berubah menjadi arah yang positif yang artinya guru tidak menjadi salah satu sumber belajar bagi siswa.

Media bangun ruang transparan adalah media 3 dimensi yang menyerupai bentuk bangun ruang kubus, balok, prisma (segitiga dan segienam) serta limas, yang terbuat dari stik es krim dan mika plastik yang mempunyai warna berbeda di setiap sisi.

Matematika menurut Ruseffendi (dalam Heruman, 2013:1) adalah matematika merupakan bahasa simbol yang berupa angka, huruf, diagram, tabel, dan lambang-lambang tertentu yang digunakan 
dalam matematika. Selain itu, matematika merupakan ilmu deduktif, dalam hal ini untuk berfikir matematika harus didasarkan pada sesuatu yang umum menuju sesuatu yang khusus. Matematika juga sebagai ilmu yang membahas tentang pola keteraturan, dan struktur yang terorganisasi, mulai dari unsur yang didefinisikan, ke aksioma atau postulat, dan akhirnya ke dalil. Setelah adanya pembuktian kebenaran maka berlaku secara umum. Sehingga dapat dikatakan bahwa matematika merupakan ilmu dasar hitung yang mempunyai fungsi sangat luas dalam berbagai aspek kehidupan. Maka dari itu, matematika hendaknya diberikan dan diajarkan seawal mungkin kepada siswa khususnya siswa sekolah dasar.

Istilah pemahaman berasal dari akar kata paham, yang menurut Kamus Besar Bahasa Indonesia (2017) diartikan sebagai pengetahuan banyak, pendapat, aliran, mengerti benar. Sedangkan istilah pemahaman sendiri yaitu perbuatan memahami atau memahamkan sesuatu. Dalam Taksonomi Bloom, pemahaman merupakan satu tingkat lebih tinggi dari pengetahuan. Pengetahuan yang dimiliki seseorang belum tentu dipahami secara mendalam, hanya sekedar mengetahui tanpa mengerti makna dari yang dipelajari. Sedangkan dengan pemahaman, seseorang tidak hanya mengetahui dan menghafal yang dipelajari, namun mampu menangkap makna dari yang dipelajari sekaligus memahami konsep dari pelajaran (Sudjana, 2016:24).

Sedangkan pengertian pemahaman siswa adalah kemampuan yang dimiliki siswa untuk dapat mengerti apa yang telah diajarkan oleh guru. Dengan kata lain, pemahaman dapat diartikan sebagai hasil dari kegiatan pembelajaran yang telah dilakukan. Pembelajaran yang mengarah pada upaya pemberian pemahaman pada siswa adalah pembelajaran yang dapat mengarahkan siswa agar dapat memahami terhadap segala sesuatu yang dipelajari. Pemahaman berbeda dengan hafalan, dimana hafalan merupakan proses pembelajaran yang dialami siswa dengan menyimpan teori sebanyak- banyaknya di dalam memorinya. Kegiatan pembelajaran seperti ini tidak efektif. Hal ini karena dalam proses pembelajaran tidak memberikan makna kepada siswa (Susanto, 2014:208).

Dilihat dari jenisnya, menurut Ruseffendi (dalam Susanto, 2014:210) ada tiga macam pemahaman matematis, yaitu: pengubahan (translation), pemberian arti (interpretation), dan pembuatan ekstrapolasi (extrapolation). Pemahaman pengubahan (translation) merupakan pemahaman yang tidak hanya pengalihan bahasa satu ke bahasa yang lainnya. Tetapi dapat mengartikan konsep abstrak menjadi simbol untuk mempermudah dalam mempelajarinya. Pemahaman pemberian arti (interpretation) merupakan pemahaman yang lebih luas dari pengubahan (translation). Pemberian arti dapat dilakukan dengan cara menghubungkan pengetahuan yang diperoleh sebelumnya, dengan menghubungkan pengetahuan baru. Pemahaman pembuatan ekstrapolasi (extrapolation) merupakan pemahaman yang lebih tinggi dari pengubahan dan pemberian arti, karena menuntut kemampuan intelektual yang lebih tinggi sehingga dituntut untuk melihat sesuatu yang tertulis.

Menurut Sudjana (2016: 25) untuk mengetahui pemahaman siswa terhadap pelajaran yang disampaikan, maka diperlukan adanya penyususnan item tes pemahaman. Adanya sebagian item tes pemahaman dapat diberikan dalam bentuk gambar, denah, diagram, dan grafik. Dalam tes objektif, tipe pilihan ganda dan tipe benar-salah banyak mengungkapkan aspek pemahaman.Uraian tersebut dapat disimpulkan bahwasannya pemahaman dalam kegiatan pembelajaran sangat penting. Hal ini dikarenakan pemahaman dibentuk dari satu kesatuan konsep yang dimiliki sejak awal, akan berdampak pada pemahaman selanjutnya. Pemahaman siswa dapat diukur dengan tes kognitif pada siswa. Oleh karena itu, antara pemahaman yang didapat siswa berdampak dengan tercapai 
atau tidaknya tujuan pembelajaran yang digunakan. Pemahaman yang dimaksud dalam penelitian ini adalah pemahaman siswa terhadap materi bangun ruang yang telah dipelajari.

Adapun ruang lingkup matematika di sekolah dasar adalah bilangan, geometri dan pengukuran, serta statistika. Geometri adalah studi tentang bangun datar dan bangun ruang dan hubungan-hubungannya (Runtukahu, 2014:149). Bangun ruang adalah suatubangun tiga dimensiyang memiliki volume (Sari, 2012:1). Sedangkan bangun tiga dimensi menurut Marini (2015:43) adalah bangun yang mempunyai panjang, lebar, dan tinggi. Pengertian bangun ruang menurut Budiyono (2016:79) adalah bangun geometri yang mempunyai luas permukaan/ luas gabungan dan isi/volume. Sehingga dapat disimpulkan bahwa pengertian bangun ruang adalah bangun tiga dimensi yang mempunyai panjang, lebar, dan tinggi yang dapat dilihat dari berbagai sudut pandang.Bangun ruang mempunyai beberapa macam, diantaranya yaitu: kubus, balok, tabung, prisma, limas, kerucut dan bola. Setiap bangun ruang mempunyai unsurunsur bangun ruang. Unsur bangun ruang adalah bagian- bagian yang ada pada bangun ruang yang meliputi bidang sisi, rusuk, titik sudut, diagonal sisi, bidang diagonal dan diagonal ruang. Unsur tersebut untuk membedakan dari masingmasing bangun ruang (Suharjana, 2008:5).

Teori belajar matematika banyak ragamnya, salah satunya dalah teori belajar kognitif, berikut ini adalah implementasi teori belajar kognitif pada pembelajaran matematika (Runtukahu, 2014:57). Menurut teori piaget dapat disimpulkan bahwa dalam memberikan materi pembelajaran kepada anak harus dimulai dari sesuatu yang konkret lalu ke abstrak.

\section{METODE}

Penelitian ini menggunakan metode penelitian percobaan (Experimen Research). Jenis penelitian yang digunakan dalam penelitian ini adalah quasi eksperimen.
Jenispenelitian quasi eksperimen menggunakan dua kelompok yaitu kelompok kontrol dan kelompok eksperimen. Penelitian ini menggunakan desain penelitian Quasi Experimental.

Tabel 1. Non equivalent control group design

\begin{tabular}{|r|c|c|}
\hline Pretest & Treatment & Posttest \\
\hline $\mathrm{O}_{1}$ & $\mathrm{X}$ & $\mathrm{O}_{2}$ \\
\hline $\mathrm{O}_{3}$ & - & $\mathrm{O}_{4}$ \\
\hline
\end{tabular}

Keterangan:

$\mathrm{O}_{1}=$ pretest kelompok eksperimen

$\mathrm{O}_{2}=$ posttest kelompok eksperimen

$\mathrm{O}_{3}=$ pretest kelompok kontrol

$\mathrm{O}_{4}=$ posttest kelompok kontrol

$\mathrm{X}=$ pembelajaran dengan menggunakan media bangun ruang transparan

(Sugiyono,2004:79)

Sampel dalam penelitian ini adalahseluruh siswa kelas II SDN Ngoro 2 dengan jumlah sebanyak 53 (lima puluh tiga) siswayang terdiri dari 27 siswa kelas IIA yang menjadi kelas kontrol dan 26 siswa kelas IIB yang menjadi kelas eksperimen.

Teknik pengumpulan data dalam penelitian ini adalah tes. Tes yang digunakan sebagai berikut : (1) Pretest dilakukan pada siswa di awal pembelajaran. Sebelum diberikan pretest, maka siswa belum diberikan perlakuan apa-apa sehingga diharapkan akan didapatkan data yang valid tentang kondisi awal siswa. (2) Posttest dilakukan pada siswa di akhir pembelajaran untuk mengetahui pemahaman yang didapatkan setelah mengalami proses belajar. Data yang digunakan dalam penelitian ini adalah data nilai pemahaman siswa. Data dikumpulkan menggunakan tes dalam bentuk pilihan ganda. Data hasil pretest dan postest dianalisis dengan menggunakan uji $\mathrm{t}$ dua sampel dengan taraf signifikansi 5\% dengan uji prasyarat yakni uji normalitas dan uji homogenitas.

Hipotesis dalam penelitian ini adalah: $\mathrm{Ha}$ : Media bangun ruang transparan berpengaruh terhadap pemahaman siswa materi bangun ruang kelas 2 SDN Ngoro II Ngoro Jombang. 
Ho : Media bangun ruang transparan tidak berpengaruh terhadap pemahaman siswa materi bangun ruang kelas 2 SDN Ngoro II Ngoro Jombang.

Teknik analisis data yang digunakan adalah sebagai berikut: (1) Uji validitas instrumen dan uji realibilitas instrumen agar instrumen yang digunakan dalam penelitian ini memenuhi syarat dan layak. (2) Uji hipotesis menggunakan uji t dua sampel yang di awali dengan a uji prasyarat yakni uji normalitas dan uji homogenitas. Uji hipotesis ini dilakukan karena dua kelompok sampel tidak saling berhubungan satu sama lain, yang artinya sampel dari kelompok kontrol tidak menjadi anggota kelompok eksperimen, dan begitu sebaliknya. Rumus yang digunkan untuk menguji hipotesis sebagai berikut:

$$
t=\frac{\overline{x_{1}}-\overline{x_{2}}}{\sqrt{\left[\frac{S D \frac{2}{1}}{N_{1}-1}\right]+\left[\frac{S D \frac{2}{1}}{N_{2}-1}\right]}}
$$

Keterangan:

$x_{1}=$ mean kelompok kontrol

$x_{2}=$ mean kelompok eksperimen

$S D_{22}=$ nilai varian kelompok kontrol

$S D_{22}=$ nilai varian kelompok eksperimen

$N_{1}=$ jumlah individu kelompok kontrol

$N_{2}=$ jumlah individu kelompok eksperimen

(Winarsunu, 2015: 75)

Jika $H_{a}$ berada di daerah penolakan $H_{o}$ (+), maka: (1) Jika $t_{\text {hitung }}>t_{\text {tabel }}$, maka Ha diterima, yaitu media bangun ruang transparan berpengaruh terhadap pemahaman siswa materi bangun ruang di SDN Ngoro 2 Ngoro Jombang. (2) Jika $t_{\text {hitung }} \leq t_{\text {tabel }}$ maka $H_{o}$ diterima, yaitu media bangun ruang transparan tidak berpengaruh terhadap pemahaman siswa materi bangun ruang di SDN Ngoro 2 Ngoro Jombang.

Jika $H_{a}$ berada di daerah penolakan $H_{O}$ (-), maka: (1) Jikat $t_{\text {hitung }} \leq t_{\text {tabel }}$, maka Ha diterima, yaitu media bangun ruang transparan berpengaruh terhadap pemahaman siswa materi bangun ruang di SDN Ngoro 2 Ngoro Jombang. (2) Jika $t_{\text {hitung }}>t_{\text {tabel }}$, maka Ho diterima, yaitu media bangun ruang transparan tidak berpengaruh terhadap pemahaman siswa materi bangun ruang di SDN Ngoro 2 Ngoro Jombang.

\section{HASIL DAN PEMBAHASAN}

Berdasarkan hasil pretest dan postest yang dilakukan terhadap kelas kontrol dan kelas eksperimen. Diperoleh data akhir sebagai berikut :

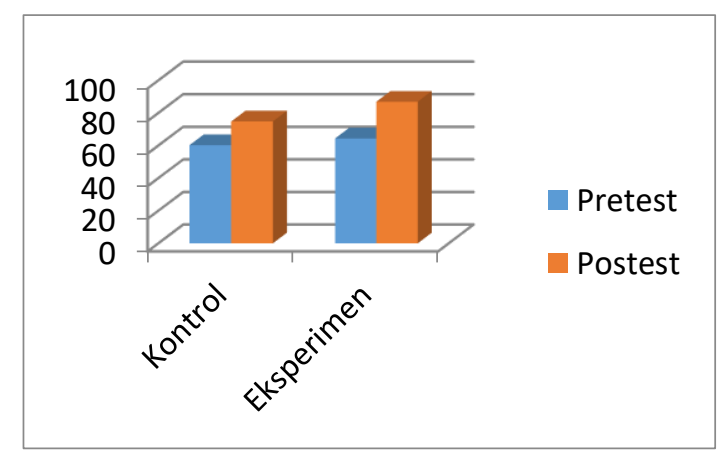

Gambar 1. Rata-rata nilai Pretest dan
Posttest

Berdasarkan hasil nilai pretest dan nilai postest baik pada kelas kontrol maupun kelas eksperimen akan diuji menggunakan uji-t (independent sampel t-test). Tetapi sebelum uji-t dilakukan, akan terlebih dahulu dilakukan uji homogenitas dan normalitas.

Uji homogenitas nilai pretest dan postest, pada uji nilai pretest skor $\mathrm{F}_{\text {hitung }} 1,09$. Skor ini dibandingkan dengan skor pada $\mathrm{F}_{\text {tabel }}$ dengan $\mathrm{db} 26$ dan 25 pada taraf signifikansi $5 \%$ yang menunjukkan nilai 1,97. Sedangkan uji nilai postest skor $F_{\text {hitung }}$ 1,04. Skor ini dibandingkan dengan skor pada $F_{\text {tabel }}$ dengan db 26 dan 25 pada taraf signifikansi $5 \%$ yang menunjukkan nilai 1,97. Karena nilai $F_{\text {hitung }}$ dibawah nilai $F_{\text {tabel }}$ maka dapat disimpulkan bahwa data nilai pretest dan postest bersifat homogen.

Uji normalitas pada kelas kontrol dan kelas eksperimen menggunakan rumus $\mathrm{x}^{2}$, yang mana uji normalitas pretest kelas kontrol 8,3 dan kelas ekpesrimen 4,89. Sedangkan uji normalitas postest kelas kontrol 10,56 dan kelas eksperimen 8,68. 
Nilai tersebut berada dibawwah nilai $\mathrm{x}^{2}$ tabel yang menunjukkan nili 11,1 untuk db 5 pada taraf signifikansi $5 \%$ yang artinya data berdistribusi normal. Setelah data dari kedua kelas dinyatakan homogen dan berdistribusi normal, maka dapat dilanjutkan dengan perhitungan uji-t.

Tabel 2. Nilai Kelompok Kontrol dan Kelompok Eksperimen

\begin{tabular}{|l|l|l|l|l|l|l|l|l|}
\hline \multirow{2}{*}{ No } & \multicolumn{4}{|c|}{ Kelompok Kontrol } & \multicolumn{4}{c|}{ Kelompok Eksperimen } \\
\cline { 2 - 9 } & Pretest & Postest & Beda $\mathbf{X}_{\mathbf{1}}$ & $\mathbf{X}_{\mathbf{1}}^{\mathbf{2}}$ & Pretest & Postest & Beda $\mathbf{X}_{\mathbf{2}}$ & $\mathbf{X}_{\mathbf{2}}^{\mathbf{2}}$ \\
\hline 1 & 40 & 60 & 20 & 400 & 46,6 & 73,3 & 26,7 & 712,89 \\
\hline 2 & 53,3 & 60 & 6,7 & 44,89 & 46,6 & 73,3 & 26,7 & 712,89 \\
\hline 3 & 80 & 80 & 0 & 0 & 53,3 & 86,6 & 33,3 & 1108,89 \\
\hline 4 & 66,6 & 73,3 & 6,7 & 44,89 & 73,3 & 100 & 26,7 & 712,89 \\
\hline 5 & 60 & 73,3 & 13,3 & 176,89 & 66,6 & 80 & 13,4 & 179,56 \\
\hline 6 & 73,3 & 86,6 & 13,3 & 0 & 73,3 & 93,3 & 20 & 400 \\
\hline 7 & 66,6 & 80 & 13,4 & 179,56 & 66,6 & 86,6 & 20 & 400 \\
\hline 8 & 60 & 60 & 0 & 176,89 & 60 & 93,3 & 33,3 & 400 \\
\hline 9 & 66,6 & 73,3 & 6,7 & 44,89 & 73,3 & 86,6 & 13,3 & 176,89 \\
\hline 10 & 53,3 & 73,3 & 20 & 400 & 60 & 80 & 20 & 400 \\
\hline 11 & 40 & 66,6 & 26,6 & 707,56 & 60 & 86,6 & 26,6 & 707,56 \\
\hline 12 & 60 & 80 & 20 & 400 & 66,6 & 80 & 13,4 & 179,56 \\
\hline 13 & 53,3 & 73,3 & 20 & 400 & 73,3 & 100 & 26,7 & 712,89 \\
\hline 14 & 66,6 & 80 & 13,4 & 179,56 & 73,3 & 93,3 & 20 & 400 \\
\hline 15 & 60 & 86,6 & 26,6 & 707,56 & 53,3 & 86,6 & 33,3 & 176,89 \\
\hline 16 & 60 & 80 & 20 & 400 & 73,3 & 86,6 & 13,3 & 176,89 \\
\hline 17 & 73,3 & 80 & 6,7 & 44,89 & 80 & 93,3 & 13,3 & 176,89 \\
\hline 18 & 60 & 80 & 20 & 400 & 53,3 & 80 & 26,7 & 712,89 \\
\hline 19 & 60 & 86,6 & 26,6 & 707,56 & 66,6 & 86,6 & 20 & 400 \\
\hline 20 & 53,3 & 66,6 & 13,3 & 400 & 66,6 & 100 & 33,4 & 1115,56 \\
\hline 21 & 46,6 & 66,6 & 20 & 400 & 80 & 100 & 20 & 400 \\
\hline 22 & 73,3 & 73,3 & 0 & 0 & 60 & 80 & 20 & 400 \\
\hline 23 & 53,3 & 66,6 & 13,3 & 176,89 & 66,6 & 86,6 & 20 & 400 \\
\hline 24 & 60 & 80 & 20 & 400 & 60 & 80 & 20 & 400 \\
\hline 25 & 60 & 73,3 & 13,3 & 176,89 & 53,3 & 73,3 & 20 & 400 \\
\hline 26 & 73,3 & 86,6 & 13,3 & 0 & 66,6 & 93,3 & 26,7 & 712,89 \\
\hline 27 & 53,3 & 73,3 & 20 & 400 & & & & \\
\hline$\sum$ & $\mathbf{1 6 2 6}$ & $\mathbf{2 0 1 9 , 2}$ & $\mathbf{3 9 3 , 2}$ & $\mathbf{7 3 6 8 , 9 2}$ & $\mathbf{1 6 7 2 , 4}$ & $\mathbf{2 2 5 9 , 2}$ & $\mathbf{5 8 6 , 8}$ & $\mathbf{1 2 6 7 6 , 0 3}$ \\
\hline Rata & $\mathbf{6 0 , 2 2}$ & $\mathbf{7 4 , 7 8}$ & & & $\mathbf{6 4 , 3 2}$ & $\mathbf{8 6 , 8 9}$ & & \\
\hline & & & & & & & & \\
\hline
\end{tabular}

Perhitungan uji-t memperoleh nilai $t_{\text {hitung }}$ sebesar $-4,49$. Nilai $t_{\text {hitung }}$ tersebut berada pada daerah penolakan Ho (-). Kemudian nilai thitung tersebut dibandingkan dengan $-\mathrm{t}_{\text {tabel }}$ untuk $\mathrm{db} 51$ pada taraf signifikansi $5 \%$ yang menunjukkan nilai 1,67. Berdasarkan kriteria yang telah ditentukan yaitu $t_{\text {hitung }}(-4,49) \leq t_{\text {tabel }}(-1,67)$, sehingga Ha dietrima.

Berdasarkan uraian diatas, dapat disimpulakan bahwa media bangun ruang transparan yang digunakan dapat mempengaruhi pemahaman siswa yang berkaitan dengan materi bangun ruang karena media bangun ruang transparan dapat mengkonkretkan materi bangun ruang yang bersifat abstrak. Hal ini sesuai dengan teori yang dikemukakan oleh Sanaky (dalam Sundayana, 2015:9) bahwa media pembelajaran dapat merangsang siswa untuk belajar yaitu dengan cara merubah konsep yang abstrak menjadi konsep yang konkret.

Tingkat pemahaman siswa juga ditunjang oleh kesesuaian tahap berpikir siswa dengan media pemebelajaran yang digunakan. Menurut Piaget (dalam Runtukahu, 2011:15) siswa sekolah dasar khususnya kelas II berda pada tahap perkembangan kognitif operasional konkret. Pada tahap ini anak belum mampu berfikir secara abstrak, siswa hanya mampu berfikir hal-hal yang nyata atau konkret yang dapat 
dilihat, dipegang, dirasakan, didengar, dan diraba dengan menggunakan alat inderanya. Berdasarkan hal tersebut, media bangun ruang transparan yang digunakan dalam penlitian ini dapat membantu siswa dalam mempelajari materi bangun ruang yang abstrak sehingga menjadi konkret.

\section{SIMPULAN}

\section{DAFTAR PUSTAKA}

Arikunto, S. 2013. Prosedur Penelitian Suatu Pendekatan dan Praktik. Jakarta: Rineka Cipta.

Budiyono. 2016. Geometri dan Pengukuran. Yogyakarta: Ombak Tiga.

Heruman. 2013. Model Pembelajaran Matematika di Sekolah Dasar. Bandung: PT.Remaja Rosdakarya.

Indah, S., \& Nur, L. 2012. Asyiknya Belajar Bangun Ruang Sisi Datar. Jakarta: PT Balai Pustaka (persero).

KBBI. 2017. Kamus Besar Bahasa Indonesia, (online), (http://kbbi.web.id/paham.html, diakses 17 Maret 2017)

Marini, A. 2015. Geometri dan Pengukuran. Bandung: PT. Remaja Rosdakarya.

Runtukahu, J.T., \& Selpius, K. 2014. Pembelajaran Matematika Dasar Bagi Anak Berkesulitan Belajar. Yogyakarta: Ar-Ruzz Media.

Sanjaya, W. 2012. Perencanaan dan Desain Sistem Pembelajaran. Jakarta: Kencana Prenada Media Group.
Berdasarkan penelitian yang telah dilakukan ini dapat disimpulan bahwa media bangun ruang transparan berpengaruh terhadap pemahaman siswa dilihat dari hasil pengujian hipotesis yang menunjukkan $t_{\text {hitung }}$ $(-4,49) \leq t_{\text {tabel }}(-1,67)$, sehingga hipotesis adanya pengaruh media bangun ruang transparan terhadap pemahaman siswa diterima.

Sudjana, N. 2016. Penilaian Hasil Proses Belajar Mengajar. Bandung: PT REMAJA ROSDAKARYA

Sugiyono. 2014. Metode Penelitian Kuantitatif, Kualitatif, dan $R \& D$. Bandung: Alfabeta.

Suharjana, A. 2008. Mengenal Bangun Ruang dan Sifat-sifatnya di Sekolah Dasar. Yogyakarta: Pusat Pengembangan dan Pemberdayaan Pendidik dan Tenaga Kependidikan Matematika.

Sundayana, R. 2015. Media dan Alat Peraga dalam Pembelajaran Matematika. Bandung: Alfabeta.

Susanto, A. 2014. Teori Belajar \& Pembelajaran di Sekolah Dasar. Jakarta: Kencana Prenamedia Group.

Trianto. 2011. Desain Pengembangan Pembelajaran Tematik Bagi Anak Usia Dini TK/RA \& Anak Usia Kelas Awal SD/MI. Jakarta: Departemen Pendidikan Nasional Republik Indonesia. 